\title{
Unass
}

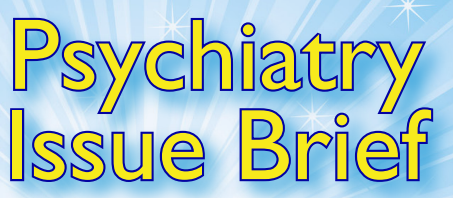

\section{Phase 1 - Community Forums Deaf ACCESS: Adapting Consent Through Community Engagement and State-Of-The-Art Simulation}

\author{
Melissa L. Anderson, Timothy Riker, Kurt Gagne, Stephanie Hakulin, Todd Higgins,
} Liz Stout, and Kelsey Cappetta

The U.S. Deaf community is a sociolinguistic minority group of 500,000 Americans who communicate using American Sign Language (ASL). This population is one of the most understudied populations in biomedical research. At this time, most research procedures are not designed to provide access to Deaf people and informed consent procedures for research are not provided in an accessible language for Deaf participants. Furthermore, because of a long history of mistreatment of Deaf people in the research world, there is a feeling of mistrust toward researchers and strong resistance to enrolling in research studies. ${ }^{1-3}$ It is vital that researchers find a way to improve access and build trust with the Deaf community to include this underserved and at-risk population in biomedical research.

In 2016, the University of Massachusetts Medical School (UMMS), in partnership with Brown University, was awarded a 2-year grant from the National Institute on Deafness and Other Communication Disorders (NIDCD) to improve Deaf people's trust and involvement in biomedical research. The Deaf ACCESS: Adapting Consent through Community Engagement and State-of-the-art Simulation research team is led by Melissa Anderson from UMMS and Co-Investigator Timothy Riker from Brown University. The study team also includes four Deaf Community Advisors. Because the research team includes five Deaf members, American Sign Language is the primary language used while working together.

\section{The Goals of Deaf ACCESS Are To:}

- Gather feedback from the Deaf community through community forums and focus groups regarding their experiences with health research and identify how researchers can better include Deaf people in research studies.

- Develop a training program for researchers related to recruiting and enrolling Deaf people in research studies, specifically the informed consent process.

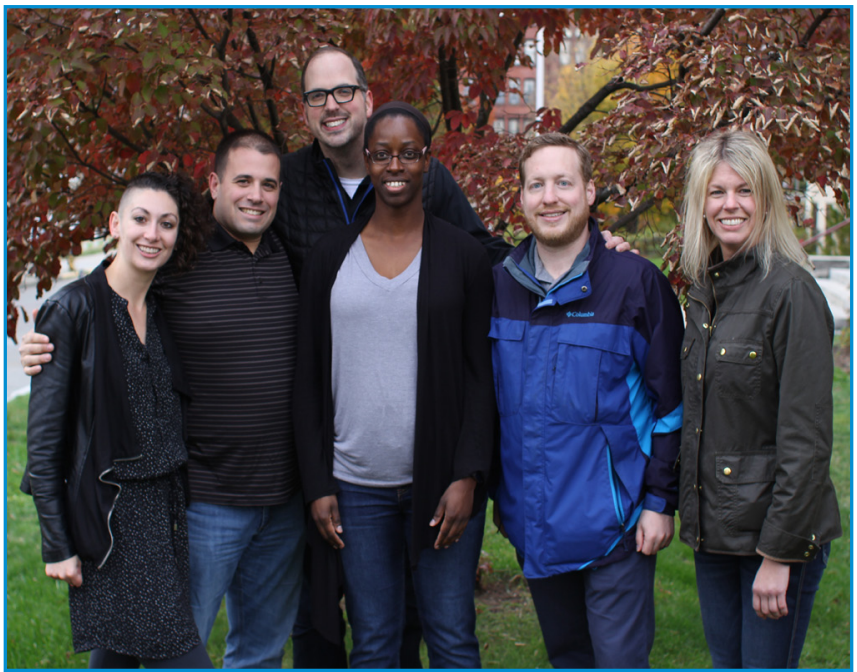

- Test and evaluate this training program with researchers and research assistants who have not previously worked with Deaf individuals.

\section{Deaf Community Forums}

During the first phase of Deaf ACCESS, the research team hosted three Deaf community forums in October and November 2016. These forums assisted the research team in identifying the barriers and facilitators to the full engagement of the Deaf community in biomedical research. The community forums were held at locations well-known and trusted by the Deaf community - Deaf schools and a Deaf independent living center.

To recruit Deaf individuals to these forums, they developed and disseminated a one-page recruitment advertisement. This ad was also converted into a brief video conducted entirely in ASL. Both the ad and video were shared in a variety of ways to reach as much of the New England Deaf community as possible.

During each forum, attendees were invited to share their experiences in the research world, and to make recommendations about how researchers can better 
include Deaf people in their studies. Hearing researchers from UMMS and other institutions were also invited to all three community forums, where they could engage in an open conversation with attendees about the historic mistreatment of Deaf and hard of hearing individuals in the research process, participate in a formal apology on behalf of the hearing research community, and collaboratively explore steps needed to move forward - an approach known as the "Truth and Reconciliation Model".

At each community forum, seating was arranged in a semi-circle format to provide full visual access to attendees. Three ASL interpreters were hired to facilitate communication between signing and non-signing attendees. Five Certified Deaf Interpreters, who are Deaf, native signers, were also present to provide specialized support to participants with various language backgrounds and communication needs. The interpreters worked together to ensure that all participants received the same information and opportunity to participate in the discussion equally. Forum discussion (in both spoken English and ASL) was recorded via five video cameras surrounding the room, simultaneously recording each sector of the semi-circle.

\section{Preliminary Results}

At the end of each community forum, attendees were asked to complete brief evaluations. Evaluation results showed that $73 \%$ of participants reported feeling positive about sharing their research experiences. $86 \%$ of participants reported that they enjoyed the opportunity to advise researchers about how to improve their work. One participant described the forum as "excellent," and indicated that they were "glad it happened." Another participant stated that there was "good information" shared, while another wrote that they were "very interested" in what was discussed.

To identify common themes discussed at the forums, the research team conducted qualitative analyses of the video footage. The most frequently reported barriers to engaging in research were the following:

- "Research in the general public is not for me"/ communication access will not be provided;

- General mistrust of hearing people due to history of negative/oppressive experiences;
- Failure of researchers to communicate study results back to the Deaf community; and

- Tendency of researchers to benefit from data provided by Deaf research participants, without any efforts to return to the Deaf community to help set-up programs or other interventions based on research findings.

\section{Next Steps}

The data collected during the Deaf community forums is being used to inform the next stages of the Deaf ACCESS project, which are:

1. Hosting four focus groups about how to adapt the informed consent process for Deaf research participants, each in ASL, with six Deaf community members.

2. Developing a prototype training intervention about how to deliver culturally appropriate informed consent using an ASL interpreter.

3. Conducting simulation-based training sessions to test the prototype's feasibility and acceptance.

4. Producing a set of guidelines for the enrollment of Deaf people in biomedical research.

\section{References}

1. Lane, H. (2005). Ethnicity, ethics, and the Deafworld. The Journal of Deaf Studies and Deaf Education, 10(3), 291-310. doi:10.1093/deafed/ eni030

2. McKee, M. M., Schlehofer, D., \& Thew, D. (2013). Ethical issues in conducting research with Deaf populations. American Journal of Public Health, 103(12), 2174-2178. doi:10.2105/AJPH.2013.301343. PMCID: PMC3966694

3. Twombley, R. (2014). To reduce health disparities, first acknowledge past research wrongs. Georgetown University Medical Center News. Retrieved from http://gumc.georgetown.edu/news/To-ReduceHealth-Disparities-First-Acknowledge-PastResearch-Wrongs

\section{IN ASL: Deaf ACCESS Research Brief 1 https://youtu.be/qmrds/pGbeQ}

\footnotetext{
Research Team: Melissa L. Anderson, PI; Timothy Riker, Co-I; Kurt Gagne, Deaf Community Advisor; Stephanie Hakulin, Deaf Community Advisor; Todd Higgins, Deaf Community Advisor; Liz Stout, Deaf Community Advisor; Kelsey Cappetta, Research Coordinator, Jonah Meehan, Deaf Community Advisor; and Emma Pici-D’Ottavio, Research Coordinator. Funding: National Institute on Deafness and Other Communication Disorders (NIDCD) 1R21DC015580-01. Time Frame: 07/20/2016 - 06/30/2018. Study Contact: Melissa Anderson: Melissa.Anderson@umassmed.edu
}

This is a product of Psychiatry Information in Brief. An electronic copy of this issue with full references can be found at http://escholarship.umassmed.edu/pib/vol14/iss6/1 